\title{
INTERSTATE BARRIERS IN THE ALCOHOLIC BEVERAGE FIELD
}

\author{
Thomas S. Green, JR.*
}

Trade barriers between states have become so numerous that many look upon them as insurmountable obstacles to a return to economic prosperity. To what extent they do obstruct the normal flow of goods in interstate commerce cannot readily be determined, nor can their effect on our economic welfare be precisely measured. It has been demonstrated, however, that these barriers have successfully shrunk or cut off state or regional markets to certain products which previously were freely distributed, and that they have stimulated economic and political sectionalism within the country.

Some 1400 restrictions, or an average of about 30 to a state, have been established by statutory provision or administrative ruling. Many others, less easily discernible, undoubtedly exist. Well over a hundred of these affect directly alcoholic beverages, and, as will presently be described, have imposed hardships on the interstate shippers of wine, beer and distilled spirits. These laws and regulations operate to the protection of producers and distributors within a state by imposing various deterrents to importations from sister states. They have led to the enactment of defensive retaliatory measures by states subject to the discriminations, and in return to counterretaliations.

Interstate trade barriers, which are the counterpart in the national scene of tariff walls erected against international trade, are for the most part offsprings of the depression. They began to find their way into the statute books in I93I, the first legislative year following its onset. In a sense their appearance was a normal development, for, as producers and distributors within a state saw their markets gradually becoming more and more restricted, it was only natural that they should turn to the state legislature for assistance. The legislature, whose sphere of jurisdiction was limited by state boundaries, followed the only immediate recourse, which was the enactment of protective measures, even though these did result in discriminations against persons in neighboring states. With amazing rapidity this practice of establishing trade barriers has multiplied and spread within the last decade until all states at the present

*A.B., I937, Williams College; M.A., I939, University of Chicago. Administrative Assistant, Defense Housing Coordinator. Formerly member of staff of Council of State Governments, Chicago. Recently engaged with the field service of the American Public Welfare Association in evaluating the Minnesota State Department of Social Security. Author of Lrouor Trade Barriers (1940), State Administration and Legislation (1939, I940) AMERICAN Yearbook, Research Bulletins on Alcoholic Beverage Trade Barriers (1939). Contributor to periodicals. 
time have enacted one or more such restrictions. Forty-three states alone are party to alcoholic beverage trade barriers. ${ }^{1}$

The situation that developed following the conclusion of the Revolutionary War offers a disturbing parallel to the present tendency. Before the adoption of the Constitution, the states economically played the roles of small independent nations, jealously protecting their own industries, and indulging in vicious commercial discriminations and reprisals. When three New England states closed their ports to British shipping, Connecticut threw hers wide open and imposed restrictions on imports from Massachusetts. On the eve of the Constitutional Convention in 1787 , New York City was conducting an interstate trade war. Its merchants saw thousands of dollars flowing out of the city in payment for firewood from Connecticut, and butter, chickens and garden vegetables from New Jersey. In order to protect the local industries, they imposed high clearance fees and duties on these imported goods. Retaliation soon took place. New Jersey taxed New York's Sandy Hook lighthouse $\$ 1800$ a year, and Connecticut organized a businessman's meeting at New London at which every merchantman signed an agreement to suspend commercial intercourse with New York City. ${ }^{2}$ Trade between these states became stagnant, and hostilities reached white heat. Comparable in nature were territorial disputes which frequently flared into minor warfares that brought interstate trade to a standstill. The quarrel between Connecticut and Pennsylvania over the Wyoming valley led to a number of armed conflicts; Vermont and New Hampshire disputed sovereignty over some Connecticut River towns, a conflict which soon involved New York and lined threatened frontiers with militia. ${ }^{3}$

One of the dominant factors in motivating the leaders of that period to frame a federal constitution and urge the adoption of a strong central government was the growing prevalence and intensity of these interstate barriers. As James Madison expressed it in a letter urging a constitutional convention:" "The practice of many states in restricting the commercial intercourse with other states and putting their productions and manufactures on the same footing with those of foreign nations, though not contrary to the Federal Articles, is certainly adverse to the spirit of the union, and tends to beget retaliating regulations, not less expensive and vexatious to themselves than they are destructive to the general harmony."

The Constitution provided that "the Congress shall have Power ... to regulate Commerce with foreign Nations, and among the several States, and with the Indian Tribes." By virtue of the delegation of supreme control over interstate commerce to the national government, a large free trade area was supposedly established. Though the commerce clause has received varying interpretations since Marshall handed down the first decision involving its construction in 1824, its enforcement by and large

\footnotetext{
${ }^{2}$ For listing of the alcoholic beverage trade barriers, see Green, Liquor Trade Barriers (Public Administration Service, r940), 27-32.

IFiske, The Criticat Pertod in American History, 1783-1789 (1888) 145-146.

3I. at 147 -I53.

"Quoted in statement of Frank Bane, infra note 7. $\quad$ Art. I, $\$ 8$.
} 
permitted the rapid settlement of the nation's vast unexplored territory, the developments of its resources, and the production and distribution of goods without significant restrictions to the flow of interstate commerce by individual state action.

A century and a half following the adoption of the Constitution, the commerce clause, as given meaning and substance by the Supreme Court justices, is showing itself less effective in preserving a free national market. State trade barriers are again emerging in our economic life, and, apparently, without violation of the legal interpretations assigned to the commerce clause, though decidedly in violation of its underlying principle. Our economy is being diverted from its traditional policy of unhampered domestic trade by a new and broader application of the residual state taxation and police powers. If these are used solely to promote the health, safety, and living standards of the people, their use is not subject to criticism. But this has not always been the effect, nor the intent. Their enforcement frequently gives economic protection to state residents by discriminating outright against the residents or products of other states, thus circumventing what the commerce clause was specifically framed to prevent.

Trade barriers affecting alcoholic beverages are to be distinguished from other trade barriers in that they are legally protected by the Twenty-first Amendment to the Constitution, ${ }^{6}$ which provides that the transportation or importation into any state of intoxicating liquors, in violation of the laws thereof, is prohibited. Congress has in substance said that the commerce clause does not apply to the interstate shipment of alcoholic beverages. The states are free to regulate domestic and imported liquors as they please. They can favor one beverage as against another, or one state as against another; they can impose any license fees, excise taxes or merchandising restrictions they may select. At their discretion, they may establish rigid prohibition, permit unrestricted importation and sale of alcoholic beverages, or adopt any regulatory program that may fit within these two extremes.

Yet, despite this legal sanctity, alcoholic beverage trade barriers differ little from other trade barriers in character or effect. Thus a few general examples will illustrate the nature and extent of these commercial discriminations established by the states under the protecting fold of state taxation and police powers. ${ }^{7}$ Under the taxation power, half the states have adopted excise taxes on oleomargarine to protect local dairy industries, and high license fees are levied on the manufacture and sale of this and other butter substitutes. In some states the excise tax does not apply if local products are used in the manufacture of oleomargarine. In a similar fashion, license fees and excise taxes are levied on the importation of other agricultural products.

A number of states which have adopted the sales tax for the raising of revenue have supplemented it with a use tax in order to cover the sales of goods imported from other states. When the law fails to provide that the use tax shall not be imposed on

\footnotetext{
${ }^{\circ}$ See supra, p. 7 ro et seq.

${ }^{7}$ See statement of Frank Bane, Exec. Dir. of the Council of State Governments. Statement to the Temporary National Economic Committee (Mar. x8, x940) 3-5.
} 
products which have paid a sales tax in the state of origin, it is generally conceded that interstate commerce is burdened more heavily than intrastate commerce, and that a trade barrier results.

Motor vehicles, especially trucks, are affected by cumulative taxes as they travel through two or more states, although reciprocity agreements in license fees are being entered into by an increasing number of states. Special license fees on independent truckers who travel from state to state are also frequently levied. One method of enforcing these requirements and of restricting importations is by port-of-entry laws, some of which often provide that motor vehicles must stop at the state border for payment of registration fees or special mileage and gasoline taxes as a condition precedent to entering the states.

The police power, implemented to protect the public health and safety, is another instrument for the enforcement of trade barriers. Ports-of-entry, besides being tax collection stations, are often used for checking equipment, weight, and insurance requirements of trucks, and so forth. The purpose is the very commendable one of insuring safety on the public highways or of collecting public revenues, but these statutes sometimes operate to obstruct the free flow of trade. Some of these ports are established to inspect and embargo plants, fruits, and vegetables, and in general to serve as quarantine stations. Quarantines are sometimes essential for the protection of public health, but they can and frequently do impose restrictions which extend beyond the minimum requirements for this objective.

Inspection requirements are also often used to control, restrict, and exclude dairy products, livestock, and horticultural and agricultural products. Sometimes these are justified in terms of public health, at other times not. For example, some states require that all milk shipped into their markets must come from dairies inspected by their agents, and then fail to provide for inspection of out-of-state dairies except in case of market shortage. Certificates testifying that livestock is pest and disease free are required in some twenty-five states, a tool that may upon occasion serve as a device to impose unnecessary discriminations. Many other legitimate regulations such as these have, under administrative ruling, developed into trade barriers.

Lack of uniform labeling laws constitutes one of the most troublesome restrictions to producers. Proper labels are imperative for adequate regulation, but when a specific state law calls for imprinting the state of origin and other extraneous information, then the intent may well be simply to foster a "buy at home" movement. Other states list detailed specifications for agricultural products, and six set a maximum grade for "fresh" eggs which in practice can be met only by domestic hens.

Many states give preference to resident laborers and contractors, and to domestic products used on public works. Many specify that public institutions can purchase only domestic products or supplies, or indirectly permit the payment of higher prices for state-produced commodities.

Even though in a few instances the states have been free to use taxation and police powers where interstate discriminations were created, such as in giving preferential 
treatment to resident laborers, contractors, and materials, ${ }^{8}$ and in exacting compensation for use of state highways, ${ }^{9}$ the Court has not neglected the principle of the commerce clause nor failed to condemn harmful barriers. In 1935, in a case which involved the constitutionality of a New York milk price-fixing agreement, Justice Cardozo stated that" ${ }^{10}$ ". . . one state . . . may not place itself in a position of economic isolation. ... Neither the power to tax nor the police power may be used by the state of destination with the aim and effect of establishing an economic barrier against competition with products of another state or the labor of its residents."

State importing regulations do not constitute interstate trade barriers merely because they impose taxes on out-of-state alcoholic beverages, and license fees or other restrictions on their distributors. To the extent that they limit distribution, curtail production, or stimulate uneconomic production, they affect adversely the normal economic processes. This is seldom brought about unless the regulatory measure provides for rate differentials or other differentials which tend to discriminate against out-of-state products and in favor of domestic ones. A trade barrier may exist in principle or in practice. If the differential remains unenforced or ineffective, the barrier is one in principle only; if it actually works an economic hardship on the importer by discriminating against him, the barrier becomes one in practice.

The Liquor Control Committee of the National Conference on Interstate Trade Barriers defined alcoholic beverage trade barriers as $:^{11}$ “. . . any legislation, rule, or regulation which is designed to subsidize or protect from competition citizens of any state who are engaged in the production or distribution of malt beverages, wines, and distilled spirits. More specifically, it refers to higher excise taxes imposed on products manufactured or packaged outside the state than are imposed on those manufactured or packaged within the state; higher license or other fees imposed on out-of-state manufacturers or wholesalers than are imposed for a like privilege on local manufacturers or wholesalers; and other shipping or merchandising restrictions directed to the same end."

So many factors influence the marketing of a product that indices for the purpose of measuring the effect of any one determinant are all but impossible to formulate. It is therefore most difficult in marginal cases to state conclusively that a law or administrative regulation which sets up differentials actually creates a trade barrier. If the differentials are large, the likelihood is that any decrease in importations since its enforcement is attributable to it; if they are small, the question is more debatable. For purposes of this discussion, therefore, all such differentials will be considered on a par, irrespective of the extent to which they probably restrict importations.

As stated above, trade barriers which restrict the state importation of alcoholic

${ }^{8}$ Atkins v. Kansas, I9I U. S. 207 (1903).

${ }^{\circ}$ Hendrick v. Maryland, 235 U. S. 6ro (1914); Kane v. New Jersey, 242 U. S. 160 (19r6); Clark v. Poor, 274 U. S. 554 (1926); Sprout v. South Bend, 277 U. S. 163 (1927); Morf v. Bingaman, 298 U. S. 407 (1935); Dixie Ohio Express Co. v. State Revenue Comm'n, 306 U. S. 72 (1939); Clark v. Paul Gray, Inc., 306 U. S. 583 (1939).

10 Baldwin v. G. A. F. Seelig, Inc., 294 U. S. 51 I, 527 (1935).

11 Nat. Conf. on Interstate Trade Barriers, Proceedings (1939) 107. 
beverages can be placed in three groups: (I) license fee differentials; (2) excise tax differentials; and (3) merchandising restrictions.

In the first group we find a number of practices. According to recent compilations, ${ }^{12} 2$ I states ${ }^{13}$ require out-of-state producers who have no place of business within the state and wish to sell to licensed wholesalers or state monopolies, to obtain a license or certificate authorizing them to do business. This fee which in substance constitutes a second license on these producers, is as high as \$rooo in Rhode Island. Although this requirement may not impose too great a hardship on large national shippers who can absorb the license cost in their general overhead without raising prices, the smaller producers may well be deterred from shipping into a trade barrier state, particularly if he sees no reasonable assurance of opening a market and reaping a profit that will cover the cost of the fee.

A discrimination is again created when wholesalers who distribute alcoholic beverages produced outside of the state are required to pay a higher license fee than those who distribute solely domestic beverages. ${ }^{14}$ This margin of difference, established in ten states, has reached the figure of $\$ 650$ (Arkansas). Naturally, the number of importing wholesalers in a state is thereby limited, and, in all probability, the amount of imported alcoholic beverages available for purchase is diminished. Higher license fees, moreover, are likely to raise prices. A third trade barrier which fits within this classification gives preferential status to local farmers. In thirteen states, ${ }^{15}$ lower license rates are given to those who manufacture from native-grown grapes than from imported grapes. Occasionally this differential may apply to fermentation by the farmers as opposed to the local wine manufacturers, but by and large this farmer subsidy is to protect the state-wide industry. Maine, for example, uses a sliding scale differential of $\$$ roo to $\$ 3000$, depending on the proportion of native to imported grapes, while other states assess two separate fees.

Excise tax differentials constitute the second group of trade barrier measures. These, affecting wine primarily, are found in eight states, ${ }^{16}$ and consist of a higher gallonage tax on imported beverages than on those domestically produced. If the difference is substantial, the imported wines will probably retail at a higher price than native wines of a comparable production cost. Such is undoubtedly the case in Arkansas, where the tax differential amounts to forty-five cents per gallon, and Michigan, where it is even one cent higher.

Among the merchandising requirements appear a number of miscellaneous provisions which tend to erect interstate trade barriers. The manufacture of beer with at least $66 \% 3$ percent barley malt is a measure adopted by five states. ${ }^{17} \mathrm{~A}$ subsidization of local barley farmers is evidently here intended, for the states which have passed

${ }^{12}$ See Green, op. cit. supra note I.

${ }^{13}$ Ala., Cal., Colo., Conn., Idaho, Me., Mass., Mich., Mo., N. H., N. J., N. M., N. Y., N. C., Pa., R. I., S. D., Tenn., Utah, Vt., Wash.

${ }_{14}$ Ark., Colo., Del., Ill., Md., Nev., Ohio, Pa., Tenn., Wash.

${ }^{10}$ Ala., Ark., Idaho, Iowa, La., Me., Md., Ore., R. I., S. C., Tex., Va., Wash.

${ }^{16}$ Ark., Ga., Me., Mich., Ore., Pa., Va., Wash. ${ }^{17}$ Iowa, Minn., N. D., Ore., Wis. 
these laws are largely agricultural. In a few instances, ${ }^{18}$ local wineries are permitted to sell directly to the consumer, while imported wines must be marketed through a licensed wholesaler. Two states, Utah and Maine, require the state liquor stores to display native-grown products in preference to out-of-state ones provided prices and quality are comparable. The issuance of manufacturers' and wholesalers' licenses is conditioned upon residence within the state from one to three years in eight ${ }^{10}$ states. Registration of brand names at a specified fee is a requisite for importation in two others. $^{20}$ Ohio has methods all its own for protecting the local wine producers. Blends must contain at least $5 \mathrm{r} \%$ native wine, and wines may not be imported in tank cars, although exportation by this method is permissible.

The exemption of exports from excise taxes, or sizeable reductions in these taxes, is a practice prevalent in nearly two thirds of the states. Though not trade barriers as here defined, but rather the converse, these measures fit into the trade barrier picture, for they assist exporters in competing on an equitable basis with alcoholic beverages in out-of-state markets, even though they may be obliged to pay certain discriminatory fees or taxes before they can ship into those markets.

Closely allied to the principle incorporated in these exemptions, but more direct and vicious in nature, are "retaliatory" and "anti-discriminatory" laws. ${ }^{21}$ Retaliations, which have received legislative approval in five states, provide that an equal discrimination shall be imposed on alcoholic beverages of states which, by their laws, discriminate against its alcoholic beverages. More far reaching are the anti-discriminations, for these prohibit in substance the state importation of all alcoholic beverages from a state which discriminates against any one of its beverages. The Indiana law is the most all-inclusive, for it permits the alcoholic beverage board to impose additional fees and taxes, to prohibit importations completely, or to enter into reciprocity agreements with discriminating states, at its discretion.

Although general economic adversity can be assigned as causal factor for the establishment of the trade barriers, the motivations behind those affecting wine, beer and distilled spirits can be more clearly defined and distinguished. Likewise, although their effects cannot always be accurately determined, some examples can be cited of the economic restrictions they have created. ${ }^{22}$

Protection of local grape-growers and their wineries can be pointed to as the main reason for adopting wine discriminations, although in a few cases they may have been promulgated primarily to increase tax collections. The arguments supporting this contention run as follows: Only a limited number of states produce enough wine from locally cultivated vineyards to export in large quantities. Among them are California, which out-produces all her sister states combined, followed, in tonnage yields, by New York, Ohio, Washington, Michigan, New Jersey, Arkansas, North

\footnotetext{
${ }^{18}$ Iowa, Wash.

${ }^{10}$ Colo., Mass., Ohio, S. D., Tex., W. Va., Wis., Wyo. $\quad{ }^{20}$ Neb., S. D.

21 Anti-discriminatory: Ala., Ind., Mich. (applies only to beer), Ore., Pa.; Retaliatory: Conn., Fla. (applies only to wine), Ohio, Pa., R. I.

${ }^{22}$ The following discussion of motivations and effects is taken from GREEN, op. cit. supra note I.
} 
Carolina, Oregon, Illinois, Minnesota, and Georgia. ${ }^{23}$ Yet 22 of the remaining states produce wine. In most of these, the grapes are grown by small farmers who allot a part of their acreage to grape vines, with the intention of fermenting on their own premises for sale in a nearby market. Since wine must be made near the site of the vineyards, because grapes are both too bulky and too perishable to be transported any great distances, it is evident that most wine production is concentrated in a few localities. This factor, along with the disparity in processing costs between small and large wineries, is the important source of wine trade barrier legislation. The small farmers and wineries fight to preserve their local markets for their own products.

The situation is somewhat different with respect to beer. In the first place, some of the necessary agricultural products are grown in only a few areas. Such is the case with hops and rice; barley is malted mainly in three states; and corn, the fourth ingredient, is grown in all states, though obtained by the brewing industry largely from the midwest farm belt. The problem, therefore, is not one of intensive competition among farmers. Where it is to be found is among the breweries. During 19371938, some 615 were listed, scattered in 40 states. Half a dozen had but one brewery, while the figures ran as high as 84 in Wisconsin and 103 in Pennsylvania. Thirteen of these states produced over a million barrels each a year, and accounted for $871 / 2 \%$ of the national total. ${ }^{24}$ Thus we find that although both farmers and brewers are interested in maintaining unrestricted interstate shipment of agricultural products, the marketing of the beer itself is subject to stiff competition between local breweries in many markets as well as between the national and local brewers. Individual brewers, most of whom do not anticipate shipping into other states, want protection in their already overcrowded markets, and seek the support of the legislature in this endeavor. In 24 beer producing states, one or more local brewers' associations have been organized, whereas only three national or regional associations exist. This further accentuates the chaotic condition of the brewing industry, and tends to place emphasis on its state rather than its national aspects.

No clearly defined causes can be attributed to trade barriers affecting distilled spirits. Only 28 states produce at all, and $98 \%$ of the total gallonage is accredited to nine states. Of this group, two have not passed any discriminatory measures and

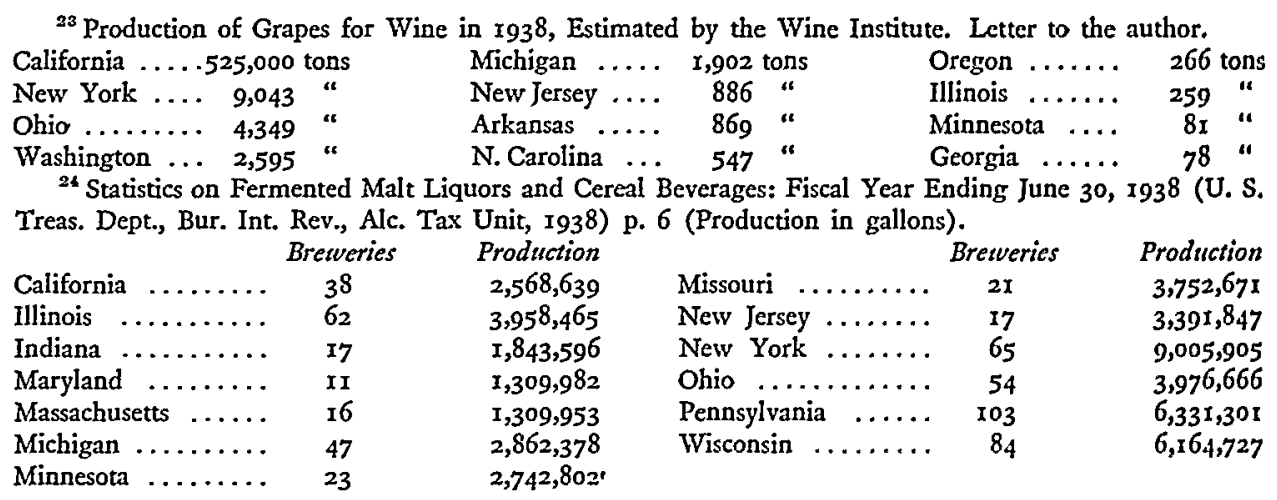


the remainder have insignificant ones. As for the raw materials, there seems to be little geographical relation to the sites of distillation. The only conclusions reached are that distilled spirits trade barriers are offshoots of the trade barrier movement and find their roots in legislation protecting beer and wine, rather than in economic factors of their own.

Motivations are important to analyze in themselves, but they only become really significant economically if the ultimate objective, that is economic protection, is accomplished. The overall effects of trade barriers on our economic life cannot accurately be determined. But specific instances in which they have created economic hardships can be isolated and analyzed.

Most of the wine produced in this country comes from California. In I938, figures were nearly 55,000,000 gallons for California and 7,500,000 gallons for the other 47 states. With the exception of California, the individual states consumed most of their own wine. California in that year, however, exported 39,000,000 gallons. Any wine trade barriers, therefore, were probably first directed at California's products. Their effect on this state has been decidedly noticeable throughout the country. Between I937 and I938, the consumption of California wine dropped over 3,000,000 gallons, while that of the other states increased by more than $2,700,000$ gallons. ${ }^{25}$

Among the other II large grape-growing states, five-Arkansas, Georgia, Michigan, Oregon, and Washington-have enacted significant discriminations by excise tax differentials. In I938, Michigan consumed less than I80,000 gallons of non-native wine, primarily as a result of a 46 cent tax differential. On the other hand, Ohio, where trade barriers are far less stringent, consumed, with only a slightly larger population, 2,400,000 gallons of non-native wine. Washington consumed less imported wine in $193^{8}$ than 1935 , at which time it had not enacted: a trade barrier law, while consumption of native wines rose from 62,000 gallons to 655,000 . A similar development is to be found in Arkansas. After the gallonage tax on out-of-state wine was increased from ten cents to $5^{\circ}$ cents, the tax on local wine remaining constant at five cents, consumption of non-native wine dropped from 323,000 gallons in 1937 to $\mathrm{r} 8 \mathrm{I}, 000$ gallons in 1938 , while that of native wines increased from 135,000 to 168,000 gallons. Most significant when examining the effects nationally of these wine trade barriers is that total consumption in the five states listed above has shrunk, whereas the per capita consumption in the other large grape-growing states has increased.

In contrast, trade barrier states which do not rank among the large producers, show, with few exceptions, increased per capita consumption figures from 1934 to 1938. A number of explanations are at hand. The trade barriers may be unimportant or ineffectively enforced. More likely, however, is that local production in these states did not meet the market requirements, and out-of-state wines were sold despite the

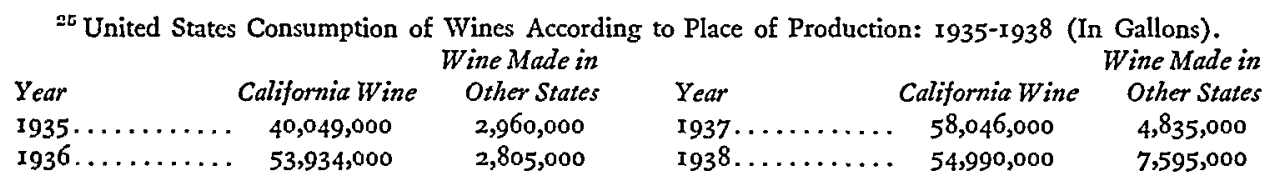


barriers and resulting higher prices. Supporting this argument of an unsaturated market are the per capita consumption figures of Indiana, a small producer-.084 gallons-compared to those of New York and California, the two largest producers, which are respectively $.75^{8}$ gallons and 3.267 gallons.

With regard to beer, less convincing factual data on the effect of trade barriers are available. It is reported that about $85 \%$ of the breweries wish to ship in interstate commerce. How many are deterred by trade barriers is difficult to determine, though some estimates have been made. ${ }^{26}$

Vermont's $\$ 750$ certificate of approval on out-of-state breweries has perhaps had the most far-reaching effects. A survey shows that although 74 breweries would like to ship into this state, only 34 actually do. In a large proportion of these cases it is the certificate which has deterred them. In New Hampshire, where the fee is $\$ 500$, only 44 out of 58 interested brewers market their beer in the local markets. Thirty-three out of 62 ship into Maine, where the certificate costs $\$$ roo. And in Colorado, which requires importing brewers to obtain a wholesaler's license at $\$ 100$ for 3.2 beer and at $\$ 500$ for heavier, reports show there are only I8 importers, although 30 breweries shipped into this state before enactment of this trade barrier law.

Another type of trade barrier has prevented many brewers from shipping into Massachusetts, New York, and New Jersey. These states impose licenses on out-ofstate solicitors, at $\$ 300, \$ 500$, and $\$ 750$ respectively. Forty-one brewers have obtained such licenses in New Jersey, but another 3I would otherwise solicit. For New York the figures are 28 and 47 , and for Massachusetts, ro and 57. Naturally, breweries can fill orders received out of the state, thus avoiding the restrictions, but breweries must convince consumers of the quality of their product first, and this is difficult to do without actually placing it in the local market.

The distilled spirits industry has undoubtedly been harmed by trade barriers. The writer has not been able to determine the extent, however. Since production is concentrated in nine states, competition in any one market is more intense between the regional or national distributors than between local distillers on the one hand and importers on the other. Hence, any trade barriers probably fail to protect local producers to any great extent.

Trade barriers are on the decline. During the I 939 legislative session, few such new laws were enacted and a number were repealed. Several groups were instrumental in bringing this about. The beer, wine and distilled spirits industries campaigned vigorously against liquor trade barriers and lobbied in all legislatures where measures were pending. The states exerted pressure on each other through retaliatory and anti-discriminatory laws. The Federal Government, first through the Federal Alcohol Administration, and later through a Joint Interdepartmental Committee on Trade Barriers, did much to reverse the trend. The most successful effort to combat the trade barrier movement, however, was that initiated by the Council of State Governments.

${ }^{26}$ Information supplied to author by U. S. Brewers' Association. 
After a few preliminary regional conferences, the Council, at the request of the Governors' Conference and its Biennial General Assembly, called a National Conference on Interstate Trade Barriers in April, 1939. Research material showing the nature and extent of the trade barrier development was prepared for this occasion. Nationwide publicity was received. The special committee, meeting to consider liquor trade barriers, called on all states to repeal existing discriminatory laws and to refrain from enacting others, and gave its approval and support to the interstate compact as a method of removing them. ${ }^{27}$ Since then, a number of follow-up regional conferences have been held. Largely due to these and to the nationwide recognition of the seriousness of this problem, trade barriers now seem to be on the decline.

To avoid regulations which tend to establish trade barriers, liquor control laws and administrative rulings should be made applicable only to in-state licenses, and possibly to out-of-state solicitors who actually do business within the state. The small local producers should naturally receive adequate protection from unethical business practices of importers, but no direct subsidization should be afforded any in-state producers. Feasible and workable methods for proper and adequate state regulation are possible without resorting to trade barriers. On these grounds, as well as because of their danger to the national economy, such discriminatory measures should be vigorously opposed.

${ }^{27}$ Loc. cit. supra note II. 